\title{
The first nationwide multicenter study of Acinetobacter baumannii recovered in Serbia: emergence of OXA-72, OXA-23 and NDM-1-producing isolates
}

Bojana Lukovic ${ }^{1 * \dagger} \mathbb{D}$, Ina Gajic ${ }^{1 * \dagger}$, Ivica Dimkic ${ }^{2}$, Dusan Kekic ${ }^{1}$, Sanja Zornic ${ }^{3}$, Tatjana Pozder ${ }^{4}$, Svetlana Radisavljevic ${ }^{5}$, Nataša Opavski ${ }^{1}$, Milan Kojic ${ }^{6}$ and Lazar Ranin ${ }^{1}$

\begin{abstract}
Background: The worldwide emergence and clonal spread of carbapenem-resistant Acinetobacter baumannii (CRAB) is of great concern. The aim of this nationwide study was to investigate the prevalence of CRAB isolates in Serbia and to characterize underlying resistance mechanisms and their genetic relatedness.

Methods: Non-redundant clinical samples obtained from hospitalized patients throughout Serbia were included in the prospective, observational, multicenter study conducted from January to June 2018. Samples were initially screened for the presence of Acinetobacter baumannii-calcoaceticus (Acb) complex using conventional bacteriological techniques. Acb complexes recovered from clinical samples obtained from inpatients with confirmed bacterial infections were further evaluated for the presence of $A$. baumannii. Identification to the species level was done by the detection of the bla $a_{\mathrm{OXA}-51}$ gene and $r p \circ B$ gene sequence analysis. Susceptibility testing was done by disk diffusion and broth microdilution method. CRAB isolates were tested for the presence of acquired

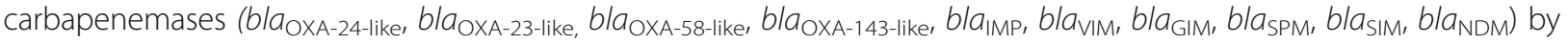
PCR. Clonal relatedness was assessed by pulsed-field gel electrophoresis (PFGE) and multilocus sequence typing (MLST).

Results: Acb complex was isolated in 280 out of 2401 clinical samples (11.6\%). Overall, A. baumannii was identified in 237 out of $280 \mathrm{Acb}$ complex (84.6\%). CRAB prevalence was found to be 93.7\% (237/222). The $\mathrm{MIC}_{50} / \mathrm{MIC}_{90}$ for imipenem and meropenem were $8 />32 \mu \mathrm{g} / \mathrm{mL}$ and $16 />32 \mu \mathrm{g} / \mathrm{mL}$, respectively. Although susceptibility was high for colistin (95.7\%; $n=227$ ) and tigecycline (75.1\%; $n=178)$, ten isolates (4.3\%) were classified as pandrug-resistant. The following carbapenemases-encoding genes were found: 98 (44.2\%) bla OXA-24-like, 76 (34.5\%) bla $a_{\text {OXA-23-like, }}$ and 7 (3.2\%) bla $a_{\text {NDM-1 }}$. PFGE analysis revealed six different clusters. MLST analysis identified three STs: ST2 $(n=13)$, ST492 $(n=14)$, and ST636 $(n=10)$. Obtained results evaluated that circulating CRAB clones in Serbia were as follows:

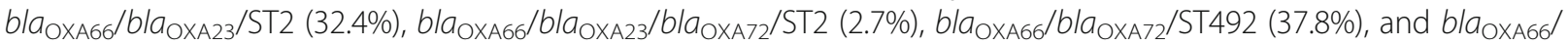
(Continued on next page)
\end{abstract}

\footnotetext{
*Correspondence: bojanall@yahoo.com; ina.gajic@yahoo.com

${ }^{\dagger}$ Bojana Lukovic and Ina Gajic contributed equally to this work. 'Institute of Microbiology and Immunology, Medical Faculty, University of Belgrade, Doktora Subotica starijeg 1, Belgrade 11000, Serbia

Full list of author information is available at the end of the article
}

C C The Author(s). 2020 Open Access This article is licensed under a Creative Commons Attribution 4.0 International License, which permits use, sharing, adaptation, distribution and reproduction in any medium or format, as long as you give appropriate credit to the original author(s) and the source, provide a link to the Creative Commons licence, and indicate if changes were made. The images or other third party material in this article are included in the article's Creative Commons licence, unless indicated otherwise in a credit line to the material. If material is not included in the article's Creative Commons licence and your intended use is not permitted by statutory regulation or exceeds the permitted use, you will need to obtain permission directly from the copyright holder. To view a copy of this licence, visit http://creativecommons.org/licenses/by/4.0/ The Creative Commons Public Domain Dedication waiver (http://creativecommons.org/publicdomain/zero/1.0/) applies to the data made available in this article, unless otherwise stated in a credit line to the data. 
(Continued from previous page)

bla OXA72/ST636 (27.1\%).

Conclusion: This study revealed extremely high proportions of carbapenem resistance among A. baumannii clinical isolates due to the emergence of bla $a_{\mathrm{OXA}-72}, b / a_{\mathrm{OXA}-23}$, and b/a $a_{\mathrm{NDM}-1}$ genes among CRAB isolates in Serbia and their clonal propagation.

Keywords: Acinetobacter baumannii, CRAB, bla $a_{\mathrm{OXA23}}$, bla $a_{\mathrm{OXA72}}$, bla $a_{\mathrm{NDM}-1}, \mathrm{ST} 492, \mathrm{ST} 636$

\section{Background}

In the recent years Acinetobacter baumannii has rapidly emerged as significant opportunistic pathogen and major cause of morbidity and mortality in the healthcare settings. The abilities of the organism to long-term survive in the hospital environment, rapidly develop antibiotic resistance and spread clonally potentiate the persistence and transmission of the species in healthcare settings. Consequently, A. baumannii is able to cause a spectrum of severe nosocomial infections such as ventilator-associated pneumonia, wound infections, bloodstream infections, meningitis, and urinary tract infections. The high risk populations are debilitating patients, those admitted to the intensive care units (ICUs), attached to indwelling foreign devices or mechanically ventilated $[1,2]$.

A. baumannii has a numerous inherent and acquired resistance mechanisms which dramatically reduce the existing therapeutic options [3]. Consequently, A. baumannii is one of the ESKAPE organisms (Enterococcus faecium, Staphylococcus aureus, Klebsiella pneumoniae, Acinetobacter baumannii, Pseudomonas aeruginosa, and Enterobacter species), a group of clinically important pathogens that have the potential for substantial antimicrobial resistance [4]. Carbapenems used to be the mainstay for the treatment of nosocomial infections caused by $A$. baumannii [3]. However, the resistance to carbapenems has rapidly emerged and resulted in the worldwide dissemination of carbapenem-resistant $A$. baumannii (CRAB) strains, which usually exhibits a multidrug-resistant (MDR) phenotype, raising serious concerns about available treatment options $[5,6]$. In addition, CRAB is one of the critical-priority pathogens on the World Health Organization priority list of antibiotic-resistant bacteria for effective drug development [7]. Moreover, in critically ill patients in the ICUs infected with MDR A. baumannii, there is a substantial rise in patient mortality rates [8]. According to the most recent data from Centers for Disease Control and Prevention $C R A B$ is listed as urgent threat in the United States with 8.500 cases and 700 deaths in hospital settings in 2017 [9].

Carbapenem resistance in Acinetobacter is mostly associated with the production of carbapenem-hydrolyzing enzymes, Ambler class D $\beta$-lactamases or oxacillinases (OXAs) [10]. Although the OXAs weakly hydrolyze carbapenems, they can confer higher resistance when $b l a_{\mathrm{OXA}}$ genes are overexpressed using a strong promoter with mobile insertion elements such as ISAba1 [11]. Less frequent, but much powerful carbapenem-hydrolyzing enzymes in $A$. baumannii belong to class $\mathrm{B} \beta$-lactamases or metallo- $\beta$-lactamases (MBLs) [10, 12].

There are numerous reports about the dissemination of CRAB strains, carriers of the OXA and MBL genes, from different geographical areas around the world [5, $12,13]$. Molecular typing of the CRAB strains from various European hospitals has shown the emergence of three successful clones originally named European clones I to III, which were renamed as international clones (ICs) I to III, after been identified worldwide [14]. In Serbia, there is no data on molecular epidemiology of CRAB in adult patients. So far, there is just one study, reporting the distribution of carbapenemase encoding genes among clinical isolates of $A$. baumannii from a single pediatric hospital [15]. However, there are several reports on OXA and MBL-positive CRAB strains, recovered from patients migrating from Serbia to Western Europe $[16,17]$.

Therefore, the aims of this nationwide multicenter study were: $i$ ) to evaluate the prevalence and antimicrobial resistance patterns of $A$. baumannii circulating in Serbia, $i i)$ to determine the prevalence of OXAs and MBLs among CRAB isolates, and iii) to assess their genetic relatedness and identify disseminated CRAB clones.

\section{Methods \\ Study design and setting}

The study was designed as a prospective, observational multicenter study. Serbia is Southeastern European country with roughly seven million inhabitants. It could be arbitrarily divided into three regions: Belgrade (the capital, two million), South Serbia (three million) and Vojvodina (two million). In the present study, regional microbiological laboratories from seven cities across Serbia evaluated 2401 randomly selected clinical specimens recovered from inpatients with confirmed bacterial infections admitted at nine hospitals throughout Serbia during the period January-June 2018. Microbiological laboratories from each region of the country evaluated 
the following number of hospital specimens: Vojvodina, $n=800$ (General hospital Subotica, General hospital Pancevo, General hospital Sombor and Institute for pulmonary diseases of Vojvodina), Belgrade, $n=801$ (University hospital medical center Bezanijska kosa, University hospital center dr Dragisa Misovic, Institute for cardiovascular diseases Dedinje), and Southern Serbia $n=800$ (Clinical center Kragujevac, Clinical center Nis). All isolated Acinetobacter calcoaceticus-baumannii (Acb) complexes were sent to the coordinating laboratory at the Institute of Microbiology and Immunology of Medical Faculty University in Belgrade for further investigation. The inclusion criteria was the isolation of the Acb complex from non-redundant clinical samples (one per infected patient) obtained during the routine laboratory work. Infection was diagnosed using corresponding clinical and laboratory criteria. The exclusion criteria were detection of the non-Acb complex microbial agents as a possible source of infection and/or isolation of Acb complex without any clinical manifestations related to infection or without positive laboratory inflammatory markers. We addressed the potential bias of misdiagnosis of infectious disease by having the diagnostic criteria validated by an independent physician. This physician was blinded in terms of medical records.

\section{Bacterial isolation and identification}

Bacterial isolation and identification of Acb complex was done during the routine work in regional clinical laboratories by $\mathrm{VITEK}^{\circ} 2$ system (bioMérieux, Marcy-l'Étoile, France) and conventional bacteriological techniques, such as colony appearance on sheep blood agar and MacConkey agar, Gram staining, motility test and biochemical characteristics.

All isolated Acb complexes together with the following data: type of specimen, ward of admission, patients' age, gender, clinical diagnosis, underlying conditions and other risk factors were sent to the coordinating laboratory for further investigation. All patients were deidentified in regional clinical laboratories and re-coded, before the bacterial strains were sent to the coordinating laboratory. The study was approved by the ethical committee of the Medical Faculty, University of Belgrade (1550/II-4).

Species identification was done in the coordinating laboratory. The DNA from an overnight culture on Columbia blood agar was extracted using a QIAamp DNA Mini Kit (QIAGEN GmbH, Hilden, Germany) according to the manufacturer's instructions. All isolates of Acb complex were initially screened for the presence of $A$. baumannii by PCR detection of the intrinsic $b l a_{\mathrm{OXA}-51}$ gene, as previously reported [18]. The primers are shown in Table 1. The species identification was then confirmed by rров gene sequence analysis, as previously described [23]. All identified A. baumannii strains were stored at $-80^{\circ} \mathrm{C}$ until further analysis.

\section{Antimicrobial susceptibility testing}

Antimicrobial susceptibility of A. baumannii to ampicillinsulbactam (AMS), piperacillin-tazobactam (TZP), ceftazidime (CAZ), cefepime (FEP), meropenem (MER), imipenem (IMP), gentamicin (GEN), amikacin (AK), tobramycin (TOB), tetracycline (TET), ciprofloxacin (CIP), levofloxacin (LEV), and trimethoprim-sulfamethoxazole (TSX) was determined by disk-diffusion assay (Bio-Rad, UK), following the Clinical and Laboratory Standards Institute (CLSI) guidelines [24]. Minimum inhibitory concentrations (MICs) for colistin (COL), IMP and MER were evaluated by ComASP Colistin (Liofilchem, Italy) and Gradient strip test (Liofilchem, Italy), respectively. MICs for tigecycline (TYG) were assessed by broth microdilution method with Mueller-Hinton broth (Bio-Rad, UK), following the CLSI guidelines [24]. Susceptibility categories were interpreted according to the CLSI criteria [24] for all antibiotics except for TYG which was interpreted according to the European Committee on Antimicrobial Susceptibility Testing (EUCAST) breakpoints for Enterobacterales $(\mathrm{S} \leq 1 \mu \mathrm{g} / \mathrm{mL}$; $\mathrm{R}>2 \mu \mathrm{g} / \mathrm{mL}$ ), since the breakpoints for TYG susceptibility against $A$. baumannii have not been determined yet [25]. Escherichia coli ATCC 25922 and Pseudomonas aeruginosa ATCC 27853 were used as quality control strains. The isolates of A. baumannii were classified as follows: multidrugresistant (MDR) [resistant to at least one agent in three or more antimicrobial categories], extensively drug-resistant (XDR) [resistant to at least one agent in all, but two or fewer antimicrobial categories] and pandrug-resistant (PDR) [resistant to all agents in all antimicrobial categories tested] [26]. Additionally, IMP resistant $A$. baumannii isolates were selected for the phenotypic detection of MBL production by imipenem-EDTA combined disk test [27].

\section{Detection of carbapenemase encoding genes and ISAbaI element}

All CRAB isolates were screened for the presence of $b l a_{\text {OXA-23-like }}, b l a_{\text {OXA-24-like, }}, b_{\text {OXA-58-like, }}, b l a_{\text {OXA-143-like, }}$ bla $a_{\mathrm{IMP}}, b l a_{\mathrm{VIM}}, b l a_{\mathrm{GIM}}, b l a_{\mathrm{SPM}}, b l a_{\mathrm{SIM}}$ and $b l a_{\mathrm{NDM}}$ with primers published elsewhere (Table 1) [19-21]. Multiplex PCRs were performed with separate groups of 4-6 primers and following the same thermal cycling conditions: initial denaturation at $94{ }^{\circ} \mathrm{C}$ for $10 \mathrm{~min}$ and $36 \mathrm{cy}$ cles of amplification consisting of $30 \mathrm{~s}$ at $94{ }^{\circ} \mathrm{C}, 40 \mathrm{~s}$ at $52^{\circ} \mathrm{C}$, and $50 \mathrm{~s}$ at $72^{\circ} \mathrm{C}$, with $5 \mathrm{~min}$ at $72^{\circ} \mathrm{C}$ for the final extension. Deionized distilled water was used as the negative control and isolates whose sequences were previously confirmed were used as the positive control. ISAba1 was detected performing uniplex PCR, as previously reported [22]. The primers are shown in Table 1. 
Table 1 Primers used in this study

\begin{tabular}{|c|c|c|c|}
\hline Primer & Sequence & Amplicon size (bp) & Reference \\
\hline OXA-51-likeF & 5'-TAATGCTTTGATCGGCCTTG-3' & 353 & [18] \\
\hline OXA-51-likeR & 5'-TGGATTGCACTTCATCTTGG-3' & & \\
\hline OXA-143-likeF & 5'-TGGCACTITCAGCAGTTCCT-3' & 149 & [19] \\
\hline OXA-143-likeR & 5'-TAATCTTGAGGGGGCCAACC-3' & & \\
\hline IMP-F & 5'-GGAATAGAGTGGCTTAAYTCTC-3' & 232 & [20] \\
\hline IMP-R & 5'-GGTTTAAYAAAACAACCACC-3' & & \\
\hline VIM-F & 5'-GATGGTGTTTGGTCGCATA-3' & 390 & [20] \\
\hline VIM-R & 5'-CGAATGCGCAGCACCAG-3' & & \\
\hline GIM-F & 5'-TCGACACACCTTGGTCTGAA-3' & 477 & {$[20]$} \\
\hline GIM-R & 5'-AACTTCCAACTITGCCATGC-3' & & \\
\hline SPM-F & 5'-AAAATCTGGGTACGCAAACG-3' & 271 & {$[20]$} \\
\hline SPM-R & 5'-ACATTATCCGCTGGAACAGG-3' & & \\
\hline SIM-F & 5'-TACAAGGGATTCGGCATCG-3' & 570 & [20] \\
\hline SIM-R & 5'-TAATGGCCTGTTCCCATGTG-3' & & \\
\hline NDM-F & 5'-GGTTTGGCGATCTGGTTTC-3' & 621 & [20] \\
\hline$N D M-R$ & 5'-CGGAATGGCTCATCACGATC-3' & & \\
\hline OXA-23-likeF & 5'-GATCGGATTGGAGAACCAGA-3' & 501 & [21] \\
\hline OXA-23-likeR & 5'-ATTTCTGACCGCATTTCCAT-3' & & \\
\hline OXA-24-likeF & 5'-GGTTAGTTGGCCCCCTTAAA-3' & 246 & [21] \\
\hline OXA-24-likeR & 5'-AGTTGAGCGAAAAGGGGATT-3' & & \\
\hline OXA-58-likeF & 5'-AAGTATTGGGGCTTGTGCTG-3' & 599 & [21] \\
\hline OXA-58-likeR & 5'-CCCCTCTGCGCTCTACATAC-3' & & \\
\hline ISAba1-F & 5'-CACGAATGCAGAAGTTG-3' & 549 & [22] \\
\hline ISAba1-R & $5^{\prime}$-CGACGAATACTATGACAC-3' & & \\
\hline
\end{tabular}

Randomly selected OXA and all MBL amplicons of CRAB isolates were purified using the QIAquick PCR Purification Kit (QIAGEN GmbH, Hilden, Germany) following manufacturer's instructions and sequenced using conventional Sanger sequencing method. The obtained sequences were searched for homology with sequenced genes in the GenBank database using the National Center for Biotechnology Information's BLAST search program 2.7.0 for nucleotides (http://www.ncbi.nlm.nih. gov). All gene sequences (manually checked) and reference strain sequences from GenBank database were aligned using CLUSTAL W implemented in BioEdit ver. 7.1.3 software.

\section{Molecular typing}

\section{Pulsed-field gel electrophoresis (PFGE) analysis}

PFGE included 60 CRAB isolates randomly selected from all participating hospitals, with respect to the specimen types and gene content. PFGE was performed with a 2015 Pulsafor unit (LKB Instruments, Broma, Sweden), as previously described [28]. DNA restriction was done with ApaI enzyme (Thermo Scientific, Lithuania). The Lambda Ladder $48.5-727.5 \mathrm{~kb}$
PFG Marker (New England Biolabs, US) was used as DNA size marker. The stained gels were scanned using the Diversity Database software image-capturing system (Bio-Rad Laboratories Ltd., UK). The Dice coefficient was used to calculate similarities of the banding patterns with a tolerance of $1.5 \%$, and the unweighted-pair group method using average linkages (UPGMA) was used for cluster analysis with BioNumerics software, version 4.0 (Applied Maths, StMartens-Latem, Belgium). The isolates with more than $80 \%$ similarity in their DNA patterns were defined as genetically related and part of the same cluster.

\section{Multilocus sequence typing (MLST) analysis}

At least $50 \%$ of the CRAB isolates from each PFGE cluster and at least one isolate from each participating hospital, endowed with different $b l a_{\mathrm{OXA}}$ gene content were selected for MLST analysis. Overall, 37 isolates were typed by MLST under the Pasteur MLST scheme which involved PCR amplification, purification and sequencing of seven housekeeping genes (fusA, gltA, pyrG, recA, сpn60, rроB, and $r p l B)$, as indicated previously [29]. Sequence types 
(STs) were assigned using the same scheme from the MLST website (http://pubmlst.org/abaumannii/).

\section{Statistical analysis}

Statistical analysis was done using SPSS version 14.0 (Chicago, Illinois USA). Statistical significance was assessed using the $\chi^{2}$ test or Fisher's exact test, as appropriate. A $P \leq 0.05$ value was considered to be significant.

\section{Results}

\section{Bacterial isolates}

During the study period, 2401 clinical samples were screened for inclusion (Fig. 1). A total of 280 (11.6\%) isolates of Acb complex recovered from clinical samples fulfilled inclusion criteria. A. baumannii was identified in 237 out of 280 isolates of Acb complex (84.6\%). Overall, the prevalence of the infections caused by $A$. baumannii were as follows: sepsis $(n=28 / 351 ; 7.9 \%)$, lower respiratory tract infections $(n=89 / 319 ; 27.9 \%)$, skin and soft tissue infections $(n=87 / 511 ; 17 \%)$, meningitis $(n=1 /$ $34 ; 2.9 \%)$, central venous catheter-related infections $(n=$ $14 / 94 ; 14.9 \%)$, and urinary tract infections $(n=18 / 1092$; $1.6 \%$ ). Most of the A. baumannii isolates were obtained from the ICU (39.6\%). Bacterial isolates were predominantly recovered from lower respiratory tract specimens (37.6\%), wound exudates (36.7\%) and blood samples (11.8\%). Majority of the patients were elderly men (median age 66; within the range 14-87). Diabetes mellitus (23.2\%) and surgical procedures (46.8\%) were the most commonly reported underlying conditions. Detail information concerning specimen types, patient characteristics, underlying conditions, and risk factors are listed in Table 2.

\section{Antimicrobial resistance}

The antibiotic resistance patterns of 237 A. baumannii isolates are shown in Table 3 . CRAB prevalence was

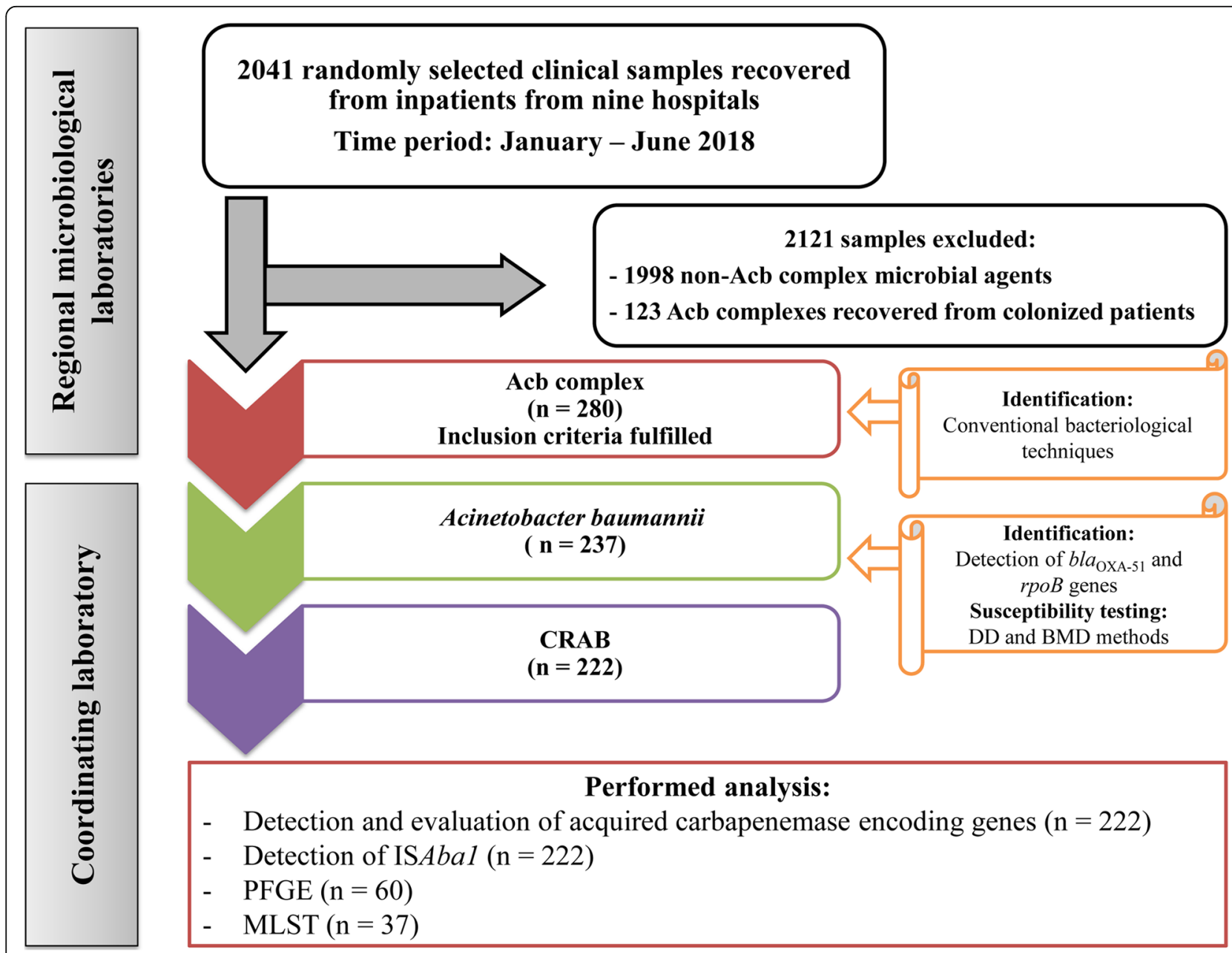

Fig. 1 Flowchart of the process of Acb complex inclusion and strain selection for further molecular evaluation. Inclusion criteria was isolation of the Acb complex from non-redundant clinical samples (one per infected patient) obtained during the routine laboratory work. Acb complex Acinetobacter calcoaceticus-baumannii complex; A. baumannii - Acinetobacter baumannii; BMD - Broth microdilution; CRAB - Carbapenem-resistant A. baumannii; DD - Disk diffusion; MLST - Multilocus sequence typing; PFGE - Pulsed-field gel electrophoresis 
Table 2 Demographic and clinical characteristics of Acinetobacter baumannii-infected study patients

\begin{tabular}{|c|c|}
\hline Characteristics & Patients No. (\%) \\
\hline \multicolumn{2}{|l|}{ Gender } \\
\hline Male & $148(62.5)$ \\
\hline Female & $89(37.5)$ \\
\hline \multicolumn{2}{|l|}{ Admission ward } \\
\hline Intensive care unit & 94 (39.6) \\
\hline Thoracic surgery & $10(4.3)$ \\
\hline Orthopedic surgery & $14(5.9)$ \\
\hline Plastic surgery & $16(6.7)$ \\
\hline Vascular surgery & $15(6.4)$ \\
\hline Neurosurgery & $9(3.8)$ \\
\hline General surgery & $12(5.1)$ \\
\hline Urology surgery & $7(2.9)$ \\
\hline Internal wards & $60(25.3)$ \\
\hline \multicolumn{2}{|l|}{ Type of specimen } \\
\hline Tracheal aspirate & $61(25.7)$ \\
\hline Bronchial aspirate & $19(8.1)$ \\
\hline Sputum & $9(3.8)$ \\
\hline Wound exudate & $87(36.7)$ \\
\hline Blood & $28(11.8)$ \\
\hline Central venous catheter tip & $14(5.9)$ \\
\hline Urine & $18(7.6)$ \\
\hline Cerebrospinal fluid & $1(0.4)$ \\
\hline \multicolumn{2}{|l|}{ Comorbidity } \\
\hline Diabetes mellitus & $55(23.2)$ \\
\hline Hypertension & $53(22.4)$ \\
\hline Heart insufficiency & $46(19.4)$ \\
\hline Cerebrovascular disease & $42(17.7)$ \\
\hline Chronic venous insufficiency & $35(14.7)$ \\
\hline Chronic obstructive lung disease & $25(10.5)$ \\
\hline Renal failure & $21(8.9)$ \\
\hline Chronic liver disease & $1(0.4)$ \\
\hline Neuromuscular disorders & 0 \\
\hline Psychiatric disorders & 0 \\
\hline Malignancy & $19(8.0)$ \\
\hline Immunological disorders & $1(0.4)$ \\
\hline Hematologic disorders & 0 \\
\hline Polytrauma & $13(5.5)$ \\
\hline Severe burns & $9(3.8)$ \\
\hline \multicolumn{2}{|l|}{ Invasive procedures } \\
\hline Any surgical procedure & $111(46.8)$ \\
\hline Mechanical ventilation & $68(28.7)$ \\
\hline Tracheostomy & $11(4.6)$ \\
\hline Central venous catheter & $46(19.4)$ \\
\hline Urinary catheter & $68(28.7)$ \\
\hline
\end{tabular}

found to be $93.7 \%$. Three isolates were resistant to MER and sensitive to IMI, while 219 (92.4\%) were resistant to both IMP and MER. Fifteen isolates (6.3\%) were fully susceptible to carbapenems. The MICs of the tested carbapenems were $2-256 \mu \mathrm{g} / \mathrm{mL}$. The $\mathrm{MIC}_{50} / \mathrm{MIC}_{90}$ for IMP and MER were $8 />32 \mu \mathrm{g} / \mathrm{mL}$ and $16 />32 \mu \mathrm{g} / \mathrm{mL}$, respectively. Carbapenem resistance rate was higher in non-invasive (94.9\%) than in invasive (92.1\%) A. baumannii isolates. However, statistical significance was not observed $(P>0.05)$. Moderate resistance rates were observed for AMS (59.1\%) and TOB (68.8\%). The drugs for which susceptibility was highest were the last-resort drugs, COL (95.7\%) and TYG (75.1\%). Thus, the MICs for $\mathrm{COL}$ ranged from $<0.25$ to $4 \mu \mathrm{g} / \mathrm{mL}$ with $\mathrm{MIC}_{50} /$ $\mathrm{MIC}_{90}$ values $<0.25 / 1 \mu \mathrm{g} / \mathrm{mL}$, while the MICs for TYG ranged from $0.125-16 \mu \mathrm{g} / \mathrm{mL}$ with $\mathrm{MIC}_{50} / \mathrm{MIC}_{90}$ values $2 / 8 \mu \mathrm{g} / \mathrm{mL}$. Resistance rates for all tested antibiotics were higher in ICU compared to other wards (Fig. 2), with the statistical significance for AMS, IMP and MER $(P<$ 0.05). Although geographical differences of the proportion of CRAB isolates were detected (Vojvodina-91.5\%; Belgrade-87.5\%; Southern Serbia-96.3\%), statistical significance was not observed $(P>0.05)$. Overall, CRAB isolates exhibited higher resistance rates to all antimicrobials as compared to carbapenems-susceptible A. baumannii (Table 3), with the exception of TYG and COL. Two hundred and three (85.6\%) isolates were considered MDR. Ninety-five isolates (40\%) displayed an XDR phenotype. Furthermore, ten isolates (4.3\%) were classified as PDR. MDR, XDR and PDR were more prevalent in the ICU than in other hospital units. The phenotypic method revealed $\mathrm{MBL}$ production in 5 (2.23\%) out of 222 CRAB strains.

\section{Detection of carbapenemase encoding genes and ISAbaI element in $A$. baumannii}

A total of 237 A. baumannii isolates harbored the naturally occurring $b l a_{\mathrm{OXA}-51^{-}}$-like gene. Out of $222 \mathrm{CRAB}$ isolates, 98 isolates $(44.2 \%)$ carried bla OXA-24-like $_{\text {and }} 76$ isolates $(34.5 \%)$ carried $b l a_{\text {OXA-23-like genes. Two isolates }}$ had both bla $a_{\text {OXA-23 }}$ and bla $a_{\text {OXA-24 }}$ genes, simultaneously. However, bla $a_{\text {OXA-58-like }}$ and bla $a_{\text {OXA-143-like genes were }}$ not detected in the tested population. Overall, ISAbaI was present in $161(71.8 \%)$ CRAB strains. The coexistence of ISAba1/bla $a_{\text {OXA-51-like, ISAba1/bla }}$ OXA-24-like, ISAba1/bla $a_{\text {OXA-23-like }}$ and $b l a_{\text {OXA-51 }} / b l a_{\text {OXA-23 }} / b l a_{\text {OXA-24 }}$ genes was detected in $16.5,28.1,26.7$, and $0.5 \%$ of CRAB strains, respectively. The $b l a_{\mathrm{NDM}}$ was the only MBL gene detected in the study $(n=7)$. Sequencing of the $b l a_{\mathrm{NDM}}$ genes in all 7 isolates revealed the presence of the $b l a_{\mathrm{NDM}-1}$ variant. Furthermore, all $b l a_{\mathrm{NDM}-1}$ positive $A$. baumannii were bla $a_{\text {OXA-24 }}$ positive isolates. None of the isolates carried bla $a_{\mathrm{IMP}}, b l a_{\mathrm{VIM}}, b l a_{\mathrm{GIM}}, b l a_{\mathrm{SPM}}$ and $b l a_{\text {SIM }}$ genes. There were no substantial differences 
Table 3 Antimicrobial resistance of the A. baumannii isolates resistant and susceptible to carbapenems

\begin{tabular}{|c|c|c|c|c|}
\hline Antimicrobial agent & $\begin{array}{l}\text { Overall resistance } \\
(\boldsymbol{n}=237) \text { No. }(\%)\end{array}$ & $\begin{array}{l}\text { Carbapenem-resistant } \boldsymbol{A} \text {. baumannii } \\
(\boldsymbol{n}=222) \text { No. (\%) }\end{array}$ & $\begin{array}{l}\text { Carbapenem-susceptibileA. baumannii } \\
(\boldsymbol{n}=15) \text { No. }(\%)\end{array}$ & $\boldsymbol{P}$ value \\
\hline Ampicillin-sulbactam & $140(59.1 \%)$ & $136(61.3)$ & $4(26.7)$ & $P=0.008$ \\
\hline Piperacillin-tazobactam & $233(98.3 \%)$ & $222(100)$ & $11(73.3)$ & $P<0.001$ \\
\hline Ceftazidime & $233(98.3 \%)$ & $222(100)$ & $11(73.3)$ & $P<0.001$ \\
\hline Cefepime & $233(98.3 \%)$ & $222(100)$ & $11(73.3)$ & $P<0.001$ \\
\hline Imipenem & $219(92.4 \%)$ & $219(98.6)$ & $0(0)$ & $P<0.001$ \\
\hline Meropenem & $222(93.7 \%)$ & $222(100)$ & $0(0)$ & $P<0.001$ \\
\hline Amikacin & $217(91.6 \%)$ & $209(94.1)$ & $8(53.3)$ & $P<0.001$ \\
\hline Gentamicin & $220(92.8 \%)$ & $210(94.6)$ & $10(66.7)$ & $P<0.001$ \\
\hline Tobramycin & $163(68.8 \%)$ & 159 (71.6) & $4(26.7)$ & $P=0.000$ \\
\hline Ciprofloxacin & $231(97.5 \%)$ & $221(99.5)$ & $10(66.7)$ & $P<0.001$ \\
\hline Levofloxacin & $226(95.4 \%)$ & $217(97.7)$ & $9(60)$ & $P<0.001$ \\
\hline Trimethoprim-sulfamethoxazole & $209(88.2 \%)$ & $202(91)$ & $6(40)$ & $P<0.001$ \\
\hline Tetracycline & $222(93.7 \%)$ & $214(96.4)$ & $8(53.3)$ & $P<0.001$ \\
\hline Tigecycline & 59 (24.9\%) & $58(26.1)$ & $1(6.7)$ & $P=0.092$ \\
\hline Colistin & $10(4.3 \%)$ & $10(4.5)$ & $0(0)$ & $P=0.401$ \\
\hline
\end{tabular}

between the hospitals and regions regarding the proportion of isolates carrying different acquired OXA genes. However, bla $a_{\mathrm{NDM}-1}$ positive isolates were detected only in two cities: Belgrade (the capital) and Nis (the city in Southern Serbia).

\section{Molecular typing}

The results of PFGE and MLST analysis of the tested CRABs, along with the information on the hospital locations, intrinsic and acquired OXA gene content are summarized in Fig. 3.

The clonal relatedness of $60 \mathrm{CRAB}$ isolates obtained from all participating hospitals was initially studied by PFGE. The similarity of the tested CRAB isolates ranged from 70 to $99 \%$. Overall, PFGE analysis revealed six different clusters (A-F) and three singletons (Fig. 3). Largest clusters $\mathrm{B}, \mathrm{C}$ and $\mathrm{D}$ which contained 5 (8.3\%), 33 (55\%), and $12(20 \%)$ isolates, respectively, were comprised of CRAB isolates from Vojvodina, Belgrade and Southern Serbia. Isolates in cluster B and C were associated with the carriage of both bla $a_{\text {OxA-24-like }}$ and $b l a_{\text {OXA-23-like }}$ carbapenemases. Isolates of the remaining four clusters [cluster A $(n=3,5 \%)$, cluster D $(n=12$, $20 \%)$, cluster $\mathrm{E}(n=2,3.3 \%)$, and cluster $\mathrm{F}(n=2,3.3 \%)]$ were more homogenous and carried only bla $a_{\text {OXA-24-like }}$ genes. Based on the PFGE clustering, OXA genes content, and hospital origin, out of $60 \mathrm{CRAB}$ isolates analyzed by PFGE, 37 were selected for further characterization by MLST and OXA gene sequencing.

MLST assigned the analyzed CRAB isolates to 3 STs: ST2 $(n=13)$, ST492 $(n=14)$, and ST636 $(n=10)$. ST2 and ST492 (a single locus variant of ST2) belonged to
ICII. ST 636 (a triple locus variant of ST2) was a singleton, not categorized in any IC. The bla $a_{\text {OXA-23 }}$ positive isolates, were all assigned to ST2, bla $a_{\mathrm{OXA}-24}$ positive belonged to ST492 and ST636, while bla $a_{\mathrm{NDM}-1}$ positive strains were identified as ST2 or ST492. All three STs were evenly distributed in Vojvodina, Belgrade and Southern Serbia. Sequencing of the acquired class D OXA genes in all selected isolates revealed the presence of the bla $a_{\mathrm{OXA}-72}$ variant in all bla $a_{\mathrm{OXA}-24-\text { like }}$ positive isolates and $b l a_{\mathrm{OXA}-23}$ allele in all $b l a_{\mathrm{OXA}-23-\text { like }}$ positive isolates. Sequencing of the intrinsic class D OXA gene identified bla $a_{\text {OXA-66 }}$ gene in all 37 isolates tested (Fig. 3). Therefore, detected clones of CRAB isolates circulating in Serbia were as follows: $b l a_{\mathrm{OXA} 66} / b l a_{\mathrm{OXA} 23} / \mathrm{ST} 2$ (32.4\%), $\quad b l a_{\text {OXA66 }} / b l a_{\text {OXA23 }} / b l a_{\text {OXA72 }} / \mathrm{ST} 2 \quad(2.7 \%)$, $b l a_{\text {OXA66 }} / b l a_{\text {OXA72 }} /$ ST492 $(37.8 \%)$, and $b l a_{\text {OXA66 }} /$ $b l a_{\text {OXA72 }} /$ ST636(27.1\%).

\section{Discussion}

A. baumannii poses a significant challenge to clinicians due to the increased incidence of hospital-acquired infections and its emergence of drug-resistance. This is the first Serbian nationwide multicenter study, providing data about the carbapenem resistance and clonality assessments of $A$. baumannii recovered from different hospitals throughout the country.

As expected, the vast majority of the Acb complexes tested in the present study was identified as A. baumannii (84.6\%). Indeed, $A$. baumannii is the species of Acb complex most frequently involved in nosocomial outbreaks or sporadic infections [13]. Results of this study indicated that the prevalence of bloodstream infections 


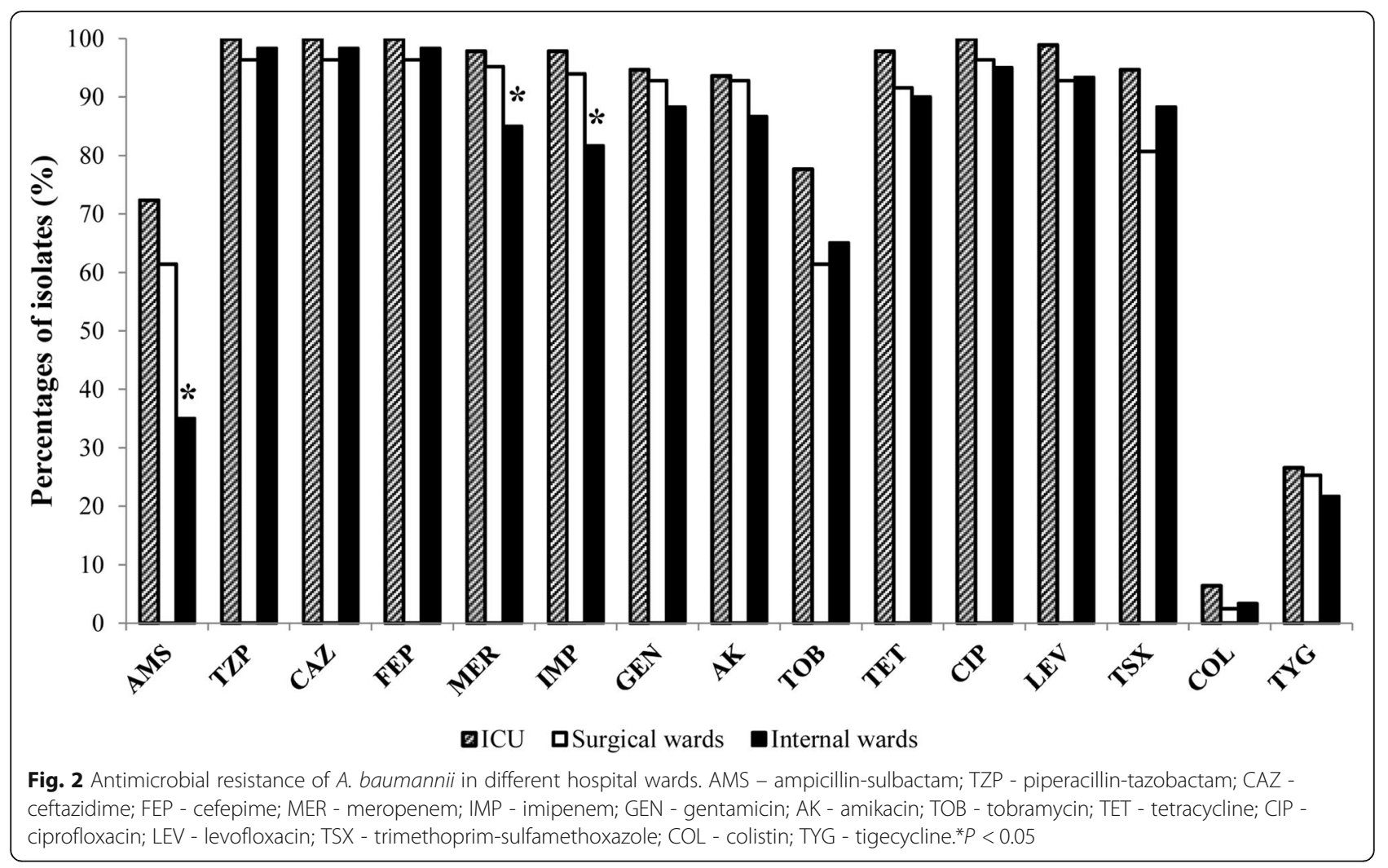

caused by A. baumannii in Serbia (7.9\%) is comparable to those found in some African and Asian countries (Morocco: 9.2\%; India: 7.5\%) [30, 31]. More than onethird of the tested $A$. baumannii recovered from clinical specimens were of respiratory origin (37.6\%). The respiratory tract has already been confirmed to be the most common isolation site of $A$. baumannii [13]. Furthermore, nearly $50 \%$ of the isolated $A$. baumannii in Mexican tertiary care hospital were of respiratory origin while a $42.6 \%$ were found in Chinese university hospital, within a 3-year study period [32, 33]. Within our study, the second most common isolation site of A. baumannii was wound tissue $(36.7 \%)$. Slightly lower isolation rates were recorded in China (burn wards: $25.2 \%$; general surgery wards: $32.2 \%$ ) [33] and in Mexico (23.2\%) [32]. It is necessary to emphasize that the high rates of our $A$. baumannii isolated from wound exudates, point out the necessity of the strict following infection control measures, especially those focusing on the minimizing the transmission rate. In addition, various risk factors noticed in the present study, have already been significantly associated with infections caused by $A$. baumannii: mechanical ventilation, indwelling catheters, and admission to the ICUs [1]. In this study, the overall CRAB prevalence was higher than $90 \%$, with IMP being a slightly more effective than MER (92.4\% vs. 93.7\%). This finding is similar to other reports of discordant susceptibilities to carbapenems, in which an isolate susceptible to imipenem but resistant to meropenem was reported $[3,34]$. Polymyxins and TYG are the only antimicrobial options for XDR Acinetobacter. Our results revealed that $C O L$ was the most active antibiotic against A. baumannii. However, the detection of 10 COL resistant isolates in this study is worrisome. Although still uncommon, A. baumannii resistance to COL has been reported from different geographic regions [35-37]. Currently, for PDR A. baumannii, limited therapeutic options exist and are usually reflected in combination therapies of two or more antibiotics [38].

Among the tested CRAB isolates, $b l a_{\mathrm{OXA}-24}$ was the most frequent carbapenemase gene (44.2\%), followed by $b l a_{\mathrm{OXA}-23}(34.5 \%)$, and $b l a_{\mathrm{NDM}-1}(3.2 \%)$. Furthermore, all sequenced bla $a_{\text {OXA-24 }}$ were identified as

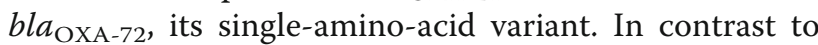
bla $a_{\text {OXA-23, }}$, which is the most common acquired carbapenemase in $A$. baumannii worldwide [5], bla $a_{\text {OXA-72 }}$ producing isolates have been reported in only several countries, including Croatia, Lithuania, and Brazil [39-41]. Results obtained in this research are in concordance with the study conducted in one pediatric hospital in Serbia, where bla $a_{\text {OXA-24 }}$ and bla $a_{\text {OXA-23 }}$ were also the most prevalent acquired OXAs among pediatric CRAB isolates [15]. Furthermore, bla $a_{\text {OXA-24 }}$ was also dominant in Bulgaria (46.7\%) and Croatia 


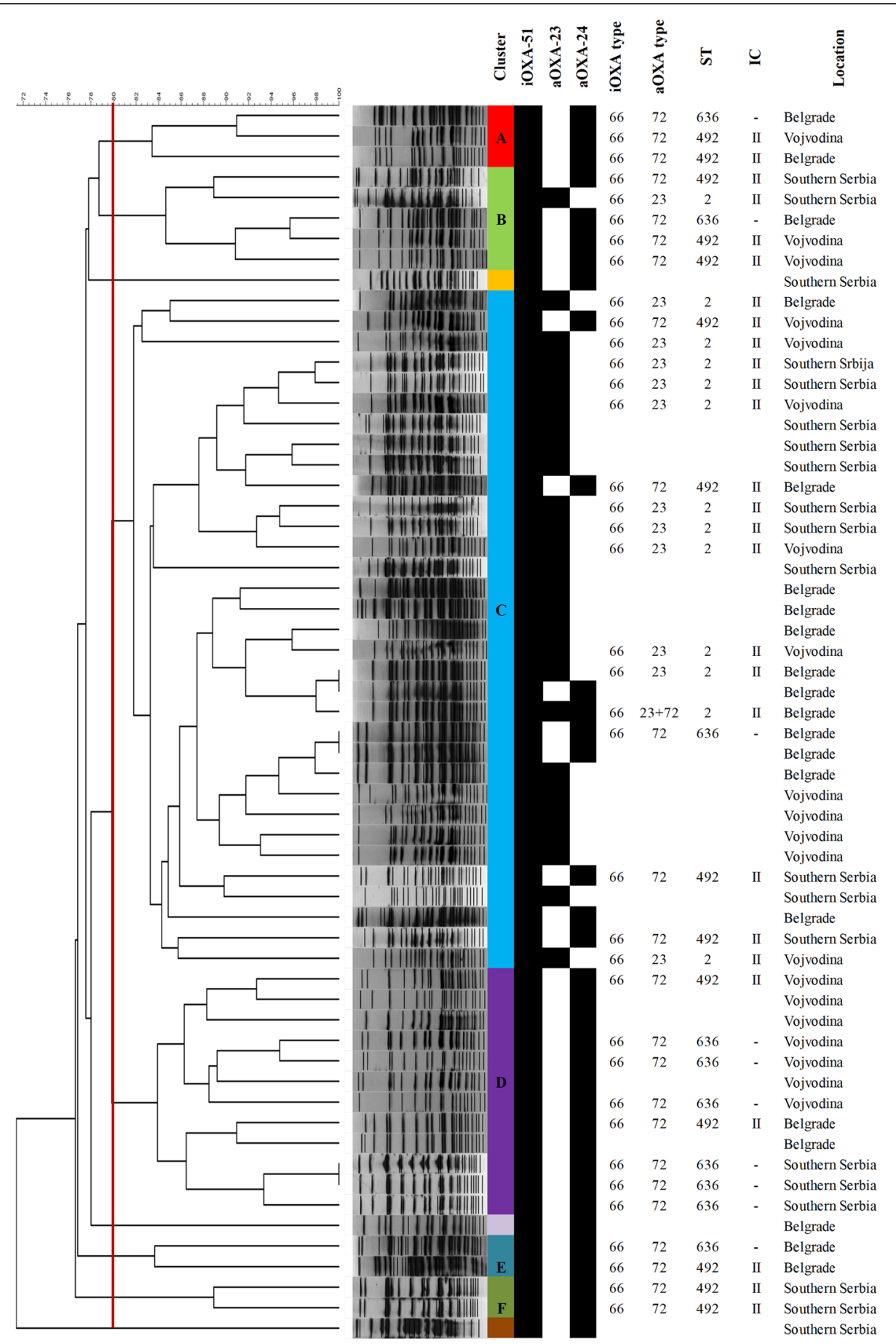

Fig. 3 Dendrogram of the pulsed-field gel electrophoresis patterns of the A. baumannii strains isolated from nine regional hospitals in Serbia showing clusters (A-F); carriage of intrinsic (iOXA) and acquired bla OXA variants (aOXA); sequence type (ST) and corresponding international clone (IC), and hospital location

(97.1\%), while $b l a_{\text {OXA-23 }}$ is globally distributed, as well as in some regional countries such as Greece (96.9\%) $[5,35,39,42]$. However, contrary to our results, Novovic et al. reported $b l a_{\text {OXA-58 }}$ in more than onethird of the tested CRAB isolated from children, indicating potential hospital dissemination of this clone [15]. Although, bla $a_{\text {OXA-58 }}$ was also detected in all three aforementioned studies from Balkan region, its prevalence was less than $3 \%$ of CRABs [35, 39, 42]. Our results are in line with other studies 
showing international shift from $b l a_{\text {OXA }-58}$ towards $b l a_{\text {OXA-23 }}$ or bla $a_{\text {OXA-24 }}[32,43-46]$.

The bla $a_{\mathrm{NDM}-1}$ carrying A. baumannii has already emerged in Europe, Asia, Africa and South America [12, 44, 47, 48]. Interestingly, two reports, from France and Germany, characterized $b l a_{\mathrm{NDM}-1}$ positive $A$. baumannii isolates obtained from patients repatriated to these countries from Serbia [16, 17]. In concordance with the above mentioned reports this study confirms that Serbia might be an endemic region for CRAB isolates carrying $b l a_{\mathrm{NDM}-1}$ genes.

In the present evaluation, MLST results correlated well with PFGE clustering. The possibility that interhospital transmission of CRAB clones have occurred in Serbia is reinforced by the detection of the majority of the PFGE patterns almost uniformly distributed throughout the country. Nevertheless, with results obtained under the Pasteur MLST scheme few genetic lineages were shown to circulate in Serbia: ST636, as a singleton along with ICII representatives (ST2 and ST492), all carrying the bla $a_{\text {OXA-66 }}$ allele of the bla $a_{\text {OXA-51-like }}$ gene. Similar to our findings, numerous reports highlighted that ICII is widely distributed in all continents, and notably in the Mediterranean area $[14,49]$. Hence, various studies indicated the worldwide distribution of the A. baumannii ST2/ICII having $b l a_{\mathrm{OXA}-23}$ gene [5]. Contrastingly to the aforementioned strain, the A. baumannii ST636 harboring $b l a_{\mathrm{OXA}-72}$ gene was isolated sporadically, from patients in Sweden, Lebanon, and one Russian patient from Germany [50-52]. Furthermore, obtained results revealed that Serbia seems to remain the reservoir for the A. baumannii pertained to ST492/ICII, carrying $b l a_{\mathrm{OXA}-72}$ and $b l a_{\mathrm{NDM}-1}$ genes. To the best of our knowledge, besides this study, there is only one case report of infection caused by $b l a_{\mathrm{OXA}-72} / b l a_{\mathrm{NDM}-1}$ producing A. baumannii, belonging to ICII/ST492, recovered from a urine sample of a Serbian patient hospitalized in France [16].

The limitation of the present study could be the small sample size of the randomly selected isolates for MLST and sequencing of the genes encoding carbapenemases. Nonetheless, despite these limitations, this nationwide research provides an important insight into the molecular epidemiology of the A. baumannii circulating in this region, especially comparing with the majority of the available European reports on $A$. baumannii which are focused on one health-care facility and particular hospital outbreak. Moreover, obtained results would serve as the base for the future studies and trend assessment of infections caused by Acinetobacter. Consequently, these data can be used to support regional initiatives to enhance infection control practices and antimicrobial stewardship, by facilitating available and inexpensive tools and resources to tackle this problem effectively and systematically.

\section{Conclusion}

In summary, this first nationwide study highlights the molecular epidemiology of the clinical isolates of $A$. baumannii. Alarming proportions of CRAB isolates are the consequences of the emergence of $b l a_{\mathrm{OXA}-72}, b l a_{\mathrm{OXA}-23}$, and $b l a_{\mathrm{NDM}-1}$ among the tested isolates. Therefore, the extremely high antimicrobial resistance rates and the emergence of certain CRAB clones point out the critical need for the implementation of continuous surveillance of infections caused by $A$. baumannii and developing accurate prevention strategies in Serbia.

\section{Abbreviations}

Acb complex: Acinetobacter calcoaceticus-baumannii complex; AK: Amikacin; AMS: Ampicillin-sulbactam; BMD: Broth microdilution; CDC: Centers for Disease Control and Prevention; CIP: Ciprofloxacin; CLSI: Clinical and Laboratory Standards Institute; COL: Colistin; CAZ: Ceftazidime;

CRAB: Carbapenem-resistant A. baumannii; EUCAST: European Committee on Antimicrobial Susceptibility Testing; FEP: Cefepime; GEN: Gentamicin; ICs: International clones; ICUs: Intensive care units; IMP: Imipenem; LEV: Levofloxacin; MBLs: Metallo- $\beta$-lactamases; MDR: Multidrug-resistant; MER: Meropenem; MICs: Minimum inhibitory concentrations; MLST: Multilocus sequence typing; PDR: Pandrug-resistant; OXAs: Oxacillinases; PFGE: Pulsed-field gel electrophoresis; STs: Sequence types; TET: Tetracycline; TOB: Tobramycin; TSX: Trimethoprimsulfamethoxazole; TYG: Tigecycline; TZP: Piperacillin-tazobactam;

XDR: Extensively drug-resistant

\section{Acknowledgments}

We gratefully acknowledge the following persons for supplying the strains used in this study: Anita Sente Zigmanovic, Desanka Mojasevic, Ljiljana Radosavljevic, Snezana Delic, Mirjana Hadnadjev, Branislava Kocic, Dragana Andjelkovic and Lidija Boskovic.

\section{Authors' contributions}

$B L, I G$, and LR participated in the protocol development, study design and study management. BL and IG participated in data interpretation and writing the manuscript. BL, IG, NO, LR, SZ, TP and SR provided the bacterial strains. $B L, I G, S Z, T P$ and SR participated in the identification of strains and performing the antimicrobial susceptibility tests. BL and IG performed PCRs and assessed the mechanisms of resistance. BL, IG and ID participated in the MLST including the analysis of gene sequences. DK and MK performed the PFGE. NO, ID and MK critically reviewed the manuscript. All authors read and approved the final manuscript.

\section{Funding}

This work was supported by the Ministry of Education, Science and Technological Development of the Republic of Serbia [Grant Nos. 175039] and the Science Fund of the Republic of Serbia [IN-DEPTH].

\section{Availability of data and materials}

All data generated or analysed during this study are included in this published article.

Ethics approval and consent to participate

The study was approved by the ethical committee of the Medical Faculty, University of Belgrade (1550/II-4).

Consent for publication

Not applicable.

Competing interests

The authors declare that they have no competing interests. 


\section{Author details}

Institute of Microbiology and Immunology, Medical Faculty, University of Belgrade, Doktora Subotica starijeg 1, Belgrade 11000, Serbia. ${ }^{2}$ Faculty of Biology, University of Belgrade, Belgrade, Serbia. ${ }^{3}$ Department of Microbiology, Clinical Center Kragujevac, Kragujevac, Serbia. ${ }^{4}$ Department of Microbiology, General Hospital Subotica, Subotica, Serbia. ${ }^{5}$ Department of Microbiology, General Hospital Pancevo, Pancevo, Serbia. ${ }^{6}$ Laboratory for Molecular Microbiology, Institute of Molecular Genetics and Genetic Engineering, University of Belgrade, Belgrade, Serbia.

Received: 13 April 2020 Accepted: 30 June 2020 Published online: 06 July 2020

\section{References}

1. Kanafani ZA, Zahreddine N, Tayyar R, Sfeir J, Araj GF, Matar GM, et al. Multidrug resistant Acinetobacter species: a seven-year experience from a tertiary care center in Lebanon. Antimicrob Resist Infect Control. 2018;7:9

2. Visca P, Seifert H, Towner KJ. Acinetobacter infection-an emerging threat to human health. IUBMB Life. 2011;63(12):1048-54.

3. Maragakis LL, Perl TM. Acinetobacter baumannii: epidemiology, antimicrobial resistance, and treatment options. Clin Infect Dis. 2008;46(8):1254-63.

4. De Rosa FG, Corcione S, Pagani N, Di Perri G. From ESKAPE to ESCAPE, from KPC to CCC. Clin Infect Dis. 2015;60(8):1289-90.

5. Mugnier PD, Poirel L, Naas T, Nordmann P. Worldwide dissemination of the blaOXA-23 carbapenemase gene of Acinetobacter baumannii. Emerg Infect Dis. 2010:16(1):35-40.

6. Perez F, Hujer AM, Hujer KM, Decker BK, Rather PN, Bonomo RA. Global challenge of multidrug-resistant Acinetobacter baumannii. Antimicrob Agents Chemother. 2007:51(10):3471-84.

7. Tacconelli E, Carrara E, Savoldi A, Harbath S, Mendelson M, Monnet DL, et al. Discovery, research, and development of new antibiotics: the WHO priority list of antibiotic-resistant bacteria and tuberculosis. Lancet Infect Dis. 2018; 18(3):318-27.

8. Falagas ME, Bliziotis IA, Siempos II. Attributable mortality of Acinetobacter baumannii infections in critically ill patients: a systematic review of matched cohort and case-control studies. Crit Care. 2006;10(2):R48

9. Centers for Disease Control and Prevention (CDC). Antibiotic resistance threats in the United States, 2019. Atlanta: U.S. Department of Health and Human Services, CDC; 2019.

10. Poirel L, Nordmann P. Carbapenem resistance in Acinetobacter baumannii: mechanisms and epidemiology. Clin Microbiol Infect. 2006;12(9):826-36.

11. Turton JF, Ward ME, Woodford N, Kaufmann ME, Pike R, Livermore DM, et al. The role of ISAba1 in expression of OXA carbapenemase genes in Acinetobacter baumannii. FEMS Microbiol Lett. 2006;258(1):72-7.

12. Bonnin RA, Poirel $L$, Naas T, Pirs M, Seme K, Schrenzel J, et al. Dissemination of New Delhi metallo- $\beta$-lactamase-1-producing Acinetobacter baumannii in Europe. Clin Microbiol Infect. 2012;18(9):e362-5.

13. Peleg AY, Seifert $H$, Paterson DL. Acinetobacter baumannii: emergence of a successful pathogen. Clin Microbiol Rev. 2008;21(3):538-82.

14. Zarrilli R, Pournaras S, Giannouli M, Tsakris A. Global evolution of multidrugresistant Acinetobacter baumannii clonal lineages. Int J Antimicrob Agents. 2013:41(1):11-9.

15. Novovic K, Mihajlovic S, Vasiljevic Z, Filipic B, Begovic J, Jovcic B. Carbapenem-resistant Acinetobacter baumannii from Serbia: revision of CarO classification. PLoS One. 2015;10(3):e0122793.

16. Dortet L, Bonnin RA, Bernabeu S, Escaut L, Vittecog D, Girlich D, et al. First occurrence of OXA-72-producing Acinetobacter baumannii in Serbia. Antimicrob Agents Chemother. 2016;60(10):5724-30.

17. Pfeifer $Y$, Wilharm G, Zander E, Wichelhaus TA, Göttig S, Hunfeld KP, et al. Molecular characterization of blaNDM-1 in an Acinetobacter baumannii strain isolated in Germany in 2007. J Antimicrob Chemother. 2011;66(9):19982001.

18. Turton JF, Woodford N, Glover J, Yarde S, Kaufmann ME, Pitt TL. Identification of Acinetobacter baumannii by detection of the blaOXA-51-like carbapenemase gene intrinsic to this species. J Clin Microbiol. 2006:44(8): 2974-6

19. Higgins $P G$, Lehmann $M$, Seifert $H$. Inclusion of OXA-143 primers in a multiplex polymerase chain reaction (PCR) for genes encoding prevalent OXA carbapenemases in Acinetobacter spp. Int J Antimicrob Agents. 2010; 35(3):305.
20. Poirel L, Walsh TR, Cuvillier V, Nordmann P. Multiplex PCR for detection of acquired carbapenemase genes. Diagn Microbiol Infect Dis. 2011;70(1):11923

21. Woodford N, Ellington MJ, Coelho JM, Turton JF, Ward ME, Brown S, et al. Multiplex PCR for genes encoding prevalent OXA carbapenemases in Acinetobacter spp. Int J Antimicrob Agents. 2006;27(4):351-3.

22. Segal H, Garny S, Elisha BG. IS IS (ABA-1) customized for Acinetobacter? FEMS Microbiol Lett. 2005;243(2):425-9.

23. La Scola B, Gundi VA, Khamis A, Raoult D. Sequencing of the rpoB gene and flanking spacers for molecular identification of Acinetobacter species. J Clin Microbiol. 2006;44(3):827-32

24. Clinical and Laboratory Standards Institute (CLSI). Performance standards for antimicrobial susceptibility testing. In: twenty-seventh informational supplement M100-S27. Wayne: Clinical and Laboratory Standards Institute; 2017.

25. European Committee on Antimicrobial Susceptibility Testing (EUCAST). Breakpoint tables for interpretation of MICs and zone diameters. Version 8.1; 2018

26. Magiorakos AP, Srinivasan A, Carey RB, Carmeli Y, Falagas ME, Giske CG, et al. Multidrug-resistant, extensively drug-resistant and pandrug-resistant bacteria: an international expert proposal for interim standard definitions for acquired resistance. Clin Microbiol Infect. 2012;18(3):268-81.

27. Yong $D$, Lee $K$, Yum JH, Shin HB, Rossolini GM, Chong Y. Imipenem-EDTA disk method for differentiation of metallo-beta-lactamase-producing clinical isolates of Pseudomonas spp. and Acinetobacter spp. J Clin Microbiol. 2002; 40(10):3798-801.

28. Kojic M, Strahinic I, Topisirovic L. Proteinase PI and lactococcin a genes are located on the largest plasmid in Lactococcus lactis subsp. lactis bv. diacetylactis S50. Can J Microbiol. 2005;51(4):305-14.

29. Diancourt L, Passet V, Nemec A, Dijkshoorn L, Brisse S. The population structure of Acinetobacter baumannii: expanding multiresistant clones from an ancestral susceptible genetic pool. PLoS One. 2010;5(4):e10034.

30. Banerjee T, Mishra A, Das A, Sharma S, Barman H, Yadav G. High prevalence and Endemicity of multidrug resistant Acinetobacter spp. in intensive care unit of a tertiary care hospital, Varanasi, India. J Pathog. 2018;2018:9129083.

31. El Kettani A, Maaloum F, Diawara I, Katfy K, Harrar N, Zerouali K, et al. Prevalence of Acinetobacter baumannii bacteremia in intensive care units of Ibn Rochd University hospital, Casablanca. Iran J Microbiol. 2017;9(6):318-23.

32. Rosales-Reyes R, Gayosso-Vázquez C, Fernández-Vázquez JL, Jarillo-Quijada MD, Rivera-Benítez C, Santos-Preciado Jl, et al. Virulence profiles and innate immune responses against highly lethal, multidrug-resistant nosocomial isolates of Acinetobacter baumannii from a tertiary care hospital in Mexico. PLoS One. 2017;12(8):e0182899.

33. Wang D, Ma L, Wu Z, Li M, Li X, Zhang W, et al. Identification and characteristics of imipenem-resistant Acinetobacter baumannii in surgical wards in a Chinese university hospital. Infect Dis (London, England). 2015; 47(3):182-6

34. Jones RN, Sader HS, Fritsche TR, Rhomberg PR. Carbapenem susceptibility discords among Acinetobacter isolates. Clin Infect Dis. 2006:42(1):158.

35. Pournaras S, Dafopoulou K, Del Franco M, Zarkotou O, Dimitroulia E, Protonotariou $\mathrm{E}$, et al. Predominance of international clone 2 OXA-23producing-Acinetobacter baumannii clinical isolates in Greece, 2015: results of a nationwide study. Int J Antimicrob Agents. 2017:49(6):749-53.

36. Qureshi ZA, Hittle LE, O'Hara JA, Rivera Jl, Syed A, Shields RK, et al. Colistinresistant Acinetobacter baumannii: beyond carbapenem resistance. Clin infect Dis. 2015;60(9):1295-303.

37. Snyman Y, Whitelaw AC, Reuter S, Dramowski A, Maloba MRB, Newton-Foot M. Clonal expansion of colistin-resistant Acinetobacter baumannii isolates in Cape Town, South Africa. Int J Infect Dis. 2020;91:94-100.

38. Leite GC, Oliveira MS, Perdigão-Neto LV, Rocha CK, Guimarães T, Rizek C, et al. Antimicrobial combinations against pan-resistant Acinetobacter baumannii isolates with different resistance mechanisms. PLoS One. 2016; 11(3):e0151270.

39. Franolić-Kukina I, Bedenić B, Budimir A, Herljević Z, Vraneš J, Higgins PG Clonal spread of carbapenem-resistant OXA-72-positive Acinetobacter baumannii in a Croatian university hospital. Int J Infect Dis. 2011:15(10): e706-9.

40. Povilonis J, Seputiene V, Krasauskas R, Juskaite R, Miskinyte M, Suziedelis K, et al. Spread of carbapenem-resistant Acinetobacter baumannii carrying a plasmid with two genes encoding OXA-72 carbapenemase in Lithuanian hospitals. J Antimicrob Chemother. 2013;68(5):1000-6. 
41. Vasconcelos AT, Barth AL, Zavascki AP, Gales AC, Levin AS, Lucarevschi BR, et al. The changing epidemiology of Acinetobacter spp. producing OXA carbapenemases causing bloodstream infections in Brazil: a BrasNet report. Diagn Microbiol Infect Dis. 2015;83(4):382-5.

42. Strateva T, Sirakov I, Stoeva T, Stratev A, Dimov S, Savov E, et al. Carbapenem-resistant Acinetobacter baumannii: current status of the problem in four Bulgarian university hospitals (2014-2016). J Glob Antimicrob Resist. 2019;16:266-73.

43. Adams-Haduch JM, Onuoha EO, Bogdanovich T, Tian GB, Marschall J, Urban CM, et al. Molecular epidemiology of carbapenem-nonsusceptible Acinetobacter baumannii in the United States. J Clin Microbiol. 2011;49(11): 3849-54.

44. Djahmi N, Dunyach-Remy C, Pantel A, Dekhil M, Sotto A, Lavigne JP. Epidemiology of carbapenemase-producing Enterobacteriaceae and Acinetobacter baumannii in Mediterranean countries. Biomed Res Int. 2014 2014:305784.

45. Schleicher $X$, Higgins $P G$, Wisplinghoff $H$, Körber-Irrgang B, Kresken $M$, Seifert H. Molecular epidemiology of Acinetobacter baumannii and Acinetobacter nosocomialis in Germany over a 5-year period (2005-2009). Clin Microbiol Infect. 2013;19(8):737-42.

46. Wang TH, Leu YS, Wang NY, Liu CP, Yan TR. Prevalence of different carbapenemase genes among carbapenem-resistant Acinetobacter baumannii blood isolates in Taiwan. Antimicrob Resist Infect Control. 2018;7:123.

47. Chen Y, Zhou Z, Jiang Y, Yu Y. Emergence of NDM-1-producing Acinetobacter baumannii in China. J Antimicrob Chemother. 2011;66(6): 1255-9.

48. Villacís JE, Bovera M, Romero-Alvarez D, Cornejo F, Albán V, Trueba G, et al. NDM-1 carbapenemase in Acinetobacter baumannii sequence type 32 in Ecuador. New Microbes New Infect. 2019;29:100526.

49. Karah N, Sundsfjord A, Towner K, Samuelsen $\varnothing$. Insights into the global molecular epidemiology of carbapenem non-susceptible clones of Acinetobacter baumannii. Drug Resist Updat. 2012;15(4):237-47.

50. Al Atrouni A, Hamze M, Jisr T, Lemarié C, Eveillard M, Joly-Guillou ML, et al. Wide spread of OXA-23-producing carbapenem-resistant Acinetobacter baumannii belonging to clonal complex II in different hospitals in Lebanon. Int J Infect Dis. 2016;52:29-36.

51. Eigenbrod T, Reuter S, Gross A, Kocer K, Günther F, Zimmermann S, et al. Molecular characterization of carbapenem-resistant Acinetobacter baumannii using WGS revealed missed transmission events in Germany from 2012-15. J Antimicrob Chemother. 2019;74(12):3473-80,

52. Karah N, Dwibedi CK, Sjöström K, Edquist P, Johansson A, Wai SN, et al. Novel aminoglycoside resistance transposons and transposon-derived circular forms detected in Carbapenem-resistant Acinetobacter baumannii clinical isolates. Antimicrob Agents Chemother. 2016;60(3):1801-18.

\section{Publisher's Note}

Springer Nature remains neutral with regard to jurisdictional claims in published maps and institutional affiliations.

Ready to submit your research? Choose BMC and benefit from:

- fast, convenient online submission

- thorough peer review by experienced researchers in your field

- rapid publication on acceptance

- support for research data, including large and complex data types

- gold Open Access which fosters wider collaboration and increased citations

- maximum visibility for your research: over $100 \mathrm{M}$ website views per year

At BMC, research is always in progress.

Learn more biomedcentral.com/submissions 